\title{
Selective removal of anti-double-stranded DNA antibodies by immunoadsorption with dextran sulphate in a patient with systemic lupus erythematosus
}

\author{
MAKIKO KINOSHITA, ${ }^{\text {SHINICHI AOTSUKA, }}{ }^{1}$ \\ TAKASHI FUNAHASHI, ${ }^{3}$ NOBUTAKA TANI, ${ }^{3}$ \\ AND RYUICHI YOKOHARI ${ }^{2}$
}

From the ${ }^{1}$ Division of Immunology, Clinical Research Institute, the ${ }^{2}$ Division of Collagen Diseases, National Medical Center, Tokyo and the ${ }^{3}$ Central Research Laboratories, Kanegafuchi Chemical Industry, Kobe $\stackrel{\oplus}{\circ}$

SUMmARY A dextran sulphate gel column removed anti-double-stranded DNA antibodies (anti-o dsDNA) selectively, efficiently, and safely from the circulation of a patient with systemic lupus erythematosus (SLE). The mechanism of the removal is thought to be due to cross reactivity ofO anti-dsDNA with dextran sulphate, which has negatively charged units. Selective removal of anti-余 dsDNA is expected to contribute not only to the treatment but also to elucidation of theo pathogenesis of SLE.

The aetiology of systemic lupus erythematosus (SLE) is unknown, but autoantibodies, especially anti-double-stranded DNA antibodies (anti-dsDNA) are thought to play an essential part in the pathogenesis of this disease. Plasmapheresis, which removes these antibodies from the circulation, has been found to be an effective treatment for patients with active SLE. ${ }^{1}$ Plasmapheresis, in general, removes plasma non-selectively and often requires the use of plasma substitute, which is expensive and may potentially cause viral hepatitis or acquired immune deficiency syndrome. Selective removal of autoantibodies is therefore preferable.

Anti-dsDNA has been shown to cross react with repeating negatively charged molecules other than DNA. ${ }^{2}$ After confirming that anti-dsDNA also had a high affinity for dextran sulphate, which has repeating negatively charged units, we tried to remove anti-dsDNA from the circulation of a patient with SLE using a dextran sulphate sorbent column, which has been used widely as a specific adsorbent for low density lipoprotein in familial hyperlipidaemia. $^{3}$

Accepted for publication 14 February 1989.

Correspondence to Dr Makiko Kinoshita, Clinical Research Institute, National Medical Center, 1-21-1 Toyama, Shinjuku-ku, Tokyo 162, Japan.

\section{Materials and methods}

BINDING OF ANTI-DNA WITH DEXTRAN SULPHATE GEL IN VITRO

Patient plasma $(0.15 \mathrm{ml})$ was mixed with $0.1 \mathrm{ml} \overrightarrow{\vec{B}}$ dextran sulphate cellulose gel suspended in $1.0 \mathrm{ml}$ TRIS-HCl buffer $(0.15 \mathrm{M}, \mathrm{pH} 7.6)$ and incubated at $\underset{P}{ }$ room temperature for two hours with stirring. The gel was centrifuged, the supernatant obtained, and the remaining gel was packed into a column and $\overline{\underline{C}}$ washed thoroughly with TRIS- $\mathrm{HCl}$ buffer. Bound $\frac{0}{3}$ antibodies were then eluted with $2 \mathrm{M} \mathrm{NaCl}$. The levels of anti-dsDNA and anti-single-stranded DNA 윽 (anti-ssDNA) antibody in the supernatant and the eluate were measured.

PLASMA SEPARATOR AND ADSORBENT As a plasma separator, hollow fibre membrane $N$ filters of polysulphone with an average pore size of $0.2 \mu \mathrm{m}$ and effective surface area of $0.5 \mathrm{~m}^{2}$ (SF 05, 응 Kanegafuchi Chemical Industry, Osaka) were used. $\omega$ Liposorber LA40 (Kanegafuchi Chemical Industry), in which $350 \mathrm{ml}$ of dextran sulphate cellulose beadso were packed, was used as a specific sorbent gel for $\overline{\mathscr{}}$ anti-dsDNA.

PROCEDURE

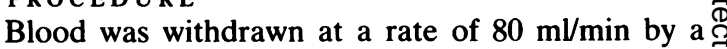


peristaltic pump through a double lumen catheter inserted into the femoral vein of the patient. Plasma was separated at a speed of $25 \mathrm{ml} / \mathrm{min}$ and passed through the Liposorber with downward flow. The filtrate was infused into the patient with the blood cell-rich portion. Total extracorporeal circulation volume was about $400 \mathrm{ml}$. For anticoagulant, heparin was injected at an initial dose of 2000 units and then continuously infused at a rate of 800 units/h. Two litres of plasma were treated for each procedure. This procedure was performed three times a week.

\section{MEA S UREM E N T}

Before and after the immunoadsorption the total blood cells were counted and biochemical data were measured with a Technicon SMAC-C (Technicon Instruments Corp, Tarrytown, NY). Before and at times when each 0.5 litre of plasma had been treated, plasma was sampled before entering and after leaving the sorbent column. The amount of cholesterol in very low density lipoprotein, low density lipoprotein, and high density lipoprotein was measured by the heparin-Ca precipitation method. $\mathrm{IgG}, \mathrm{IgA}, \mathrm{C} 3$, and $\mathrm{C} 4$ were measured by laser nephelometry. Titres of anti-dsDNA and antissDNA were measured by enzyme linked immunosorbent assay (ELISA) using dsDNA and ssDNA, obtained according to the methods described by Aotsuka et al, ${ }^{4}$ as antigens. Immune complexes were measured by a modified $\mathrm{Clq}$ solid phase binding test. $^{5}$ Antinuclear ribonucleoprotein antibodies (anti-nRNP) were measured by an ELISA using affinity column purified $\mathrm{nRNP}$ as antigen. ${ }^{6}$

\section{Case report}

A 30 year old man was admitted to our hospital on 29 May 1987 for further evaluation of SLE. In October 1986 he had experienced a fever of $40^{\circ} \mathrm{C}$ with polyarthralgia and malar rash. After a diagnosis of SLE he was given $60 \mathrm{mg}$ prednisolone and subsequently improved. In April 1987 he suddenly had two episodes of syncope attack. On 29 May he visited our outpatient clinic and was admitted for further evaluation. He was $175 \mathrm{~cm}$ in height and 65 $\mathrm{kg}$ in weight. Physical examination on admission showed no abnormality. On laboratory examination the white blood cell count was $8.8 \times 10^{9} / 1$, red blood cell count $4 \cdot 8 \times 10^{12} / 1$, and platelet count $303 \times 10^{y} / 1$. Biochemical data showed no abnormality. LE test and LE cell phenomenon were positive and a serological test for syphilis was negative. IgA was $2.56 \mathrm{~g} / 1, \mathrm{IgG} 14.63 \mathrm{~g} / 1$, IgM $0.42 \mathrm{~g} / \mathrm{l}, \mathrm{C} 31.32 \mathrm{~g} / \mathrm{l}$, and $\mathrm{C} 40 \cdot 13 \mathrm{~g} / \mathrm{l}$. Fluorescence antinuclear antibody was positive at a titre of $1 / 2560$ in a speckled pattern. IgG anti-dsDNA was $149 \mathrm{U} / \mathrm{ml}$, IgM anti-dsDNA 19 $\mathrm{U} / \mathrm{ml}$, IgG anti-ssDNA $426 \mathrm{U} / \mathrm{ml}$, and IgM antissDNA $200 \mathrm{U} / \mathrm{ml}$, whereas the normal ranges of these anti-DNA are all less than $100 \mathrm{U} / \mathrm{l}$. AntinRNP was positive at a titre of $1 / 320$ by passive haemagglutination test. Anti-Sm antibody was negative. Urine analysis, electrocardiogram, chest $x$ ray, electroencephalogram, spinal fluid analysis, and brain computed tomogram were all normal. He fulfilled the 1982 American Rheumatism Association revised criteria for SLE. The $30 \mathrm{mg}$ of prednisolone that he was taking on admission was decreased to $25 \mathrm{mg}$ at day 14. After a few days he

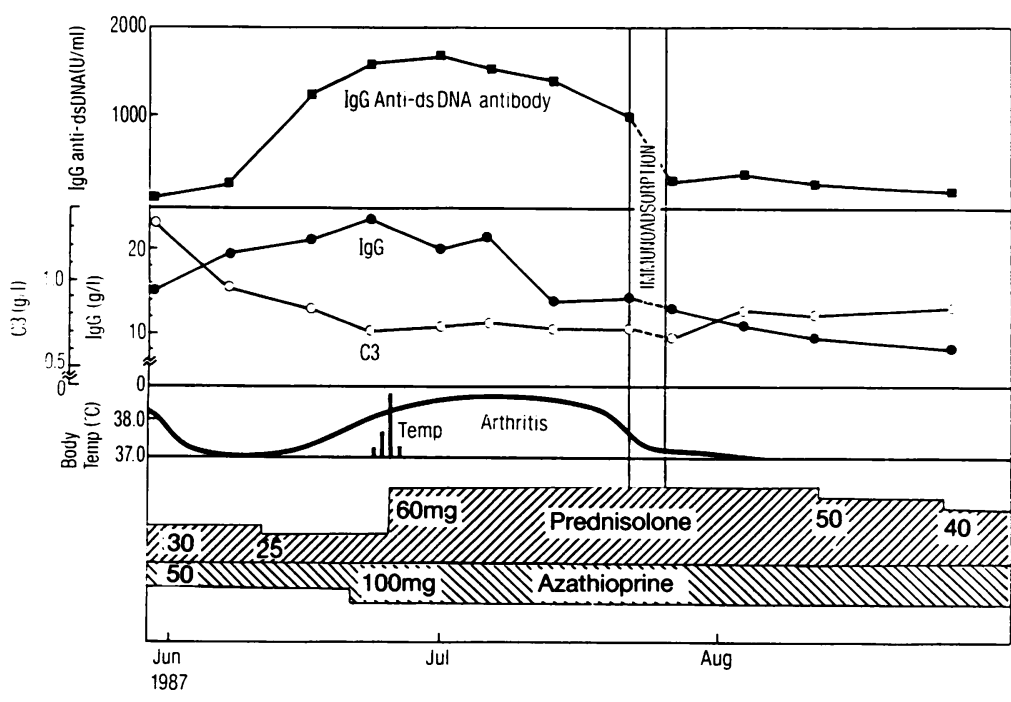

Fig. 1 Clinical course and titres of IgG anti-dsDNA antibodies, IgG, and $C 3$. 
Table 1 Values of recovery rate $(R)$ of plasma components. Values represent the mean (SD) of three procedures

\begin{tabular}{|c|c|}
\hline Plasma component & $R^{*}$ \\
\hline 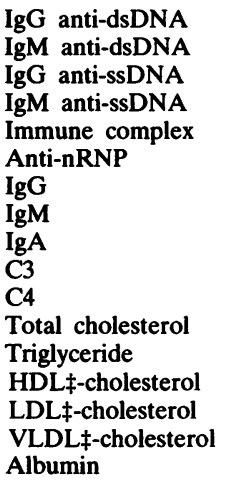 & $\begin{array}{l}0.596(0.099) \\
0.661(0.050) \\
0.672(0.093) \\
0.658(0.053) \\
0.637(0.099) \\
0.919(0.064) \\
0.945(0.073) \\
0.965(0.052) \\
0.951(0.047) \\
0.927(0.040) \\
0.870(0.090) \\
0.537 \dagger \\
0.262 \\
0.800 \\
0.527 \\
0.274 \\
0.971\end{array}$ \\
\hline
\end{tabular}

${ }^{*} \mathrm{R}$ is the recovery rate calculated as the ratio of final to initial concentration.

†Standard deviation is not given where there was only one measurement.

$\ddagger \mathrm{HDL}=$ high density lipoprotein; $\mathrm{LDL}=$ low density lipoprotein; VLDL $=$ very low density lipoprotein.

began to suffer from polyarthritis. On day 27 he developed a fever of $39^{\circ} \mathrm{C}$. Increase of the antidsDNA titre and decrease of serum complement were also noted. Sixty milligrams of prednisolone was given and the fever subsided. Polyarthritis, however, did not ameliorate and the titre of
anti-dsDNA remained high despite treatment with $亏$ $60 \mathrm{mg}$ prednisolone and $100 \mathrm{mg}$ of azathioprine for 므. one month. After confirming that his anti-dsDNA bound to dextran sulphate in vitro, we gave immunoadsorbent treatment using the Liposorber, with the patient's agreement.

Results

A study of the binding of anti-DNA with dextran on sulphate gel in vitro showed that the titres of anti- $\vec{O}$ dsDNA and anti-ssDNA in the supernatant of the dextran sulphate gel were $22.3 \%$ and $34.2 \%$ that of $\vec{\omega}$ the original plasma respectively, whereas those of the eluate were $71.0 \%$ and $63.5 \%$ respectively.

Figure 1 shows the clinical course and the level of $\stackrel{p}{\stackrel{p}{\circ}}$ IgG class anti-dsDNA. His anti-dsDNA began to $\vec{\circ}$ rise as the prednisolone was decreased from 30 to $\infty$ $25 \mathrm{mg}$. After treatment with $60 \mathrm{mg}$ prednisolone for one month a $30 \%$ decrease in the level of IgG anti- 윽 dsDNA was noted. Immunoadsorption was able to remove $77.2 \%$ of the IgG anti-dsDNA during three $O$ procedures over a one week period. There was no 0 rebound phenomenon. Clinical improvement after $\underset{\Phi}{ }$ immunoadsorption was not clear. Fever subsided immediately after treatment with $60 \mathrm{mg}$ prednisolon $\AA$ Arthritis, which continued even after one month treatment with $60 \mathrm{mg}$ prednisolone, began ameliorate on the morning of immunoadsorption: There were no side effects during or after immunoadsorption.

To estimate the capacity of the sorbent column $\stackrel{\mathbb{Q}}{\mathbb{Q}}$ the recovery rate $(R)$ was calculated $(R=C f / C i, \stackrel{\vec{F}}{\overrightarrow{3}}$

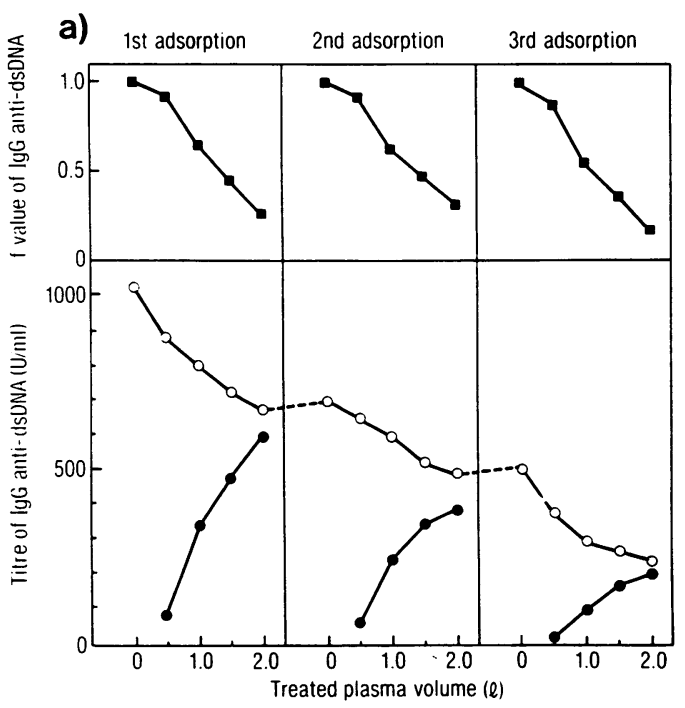

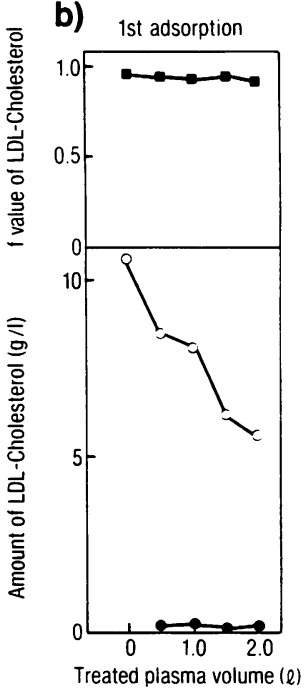

Fig 2 (a) Titres of IgG anti-dsDNA antibodies and trapping coefficient $f \bar{\varrho}$ during three immunoadsorption procedures. The $f$ value is defined as $f=1-C a / C b$, where $C a$ and $C b$ are the concentrations of a plasma compone after and before the immunoadsorbeng column. $\mathrm{O}-\mathrm{O}=$ titres of $\mathrm{Ig} G$ anti-dsDNA antibodies in plasma obtained before the immunoadsorption column; -1 =those after the immunoadsorbent column, value of IgG anti-dsDNA. (b) Amoude of low density lipoprotein $(L D L)$-cholesterol and $f$ value of first immunoadsorption. $\mathrm{O}-\mathrm{O}=$ amoun of $L D L$-cholesterol in plasma obtained before the immunoadsorbent column; =amount after the immunoadsorbent column; $\square$ value of LDL-cholesterol. 
where $\mathrm{Cf}$ and $\mathrm{Ci}$ are the final and initial concentrations respectively). The recovery rate of $\mathrm{IgG}$ antidsDNA was 0.596 (SD 0.099) and recovery rates of IgM anti-dsDNA, IgG anti-ssDNA, IgM antissDNA were almost the same as that of IgG antidsDNA (Table 1). One session of immunoadsorption was able to reduce anti-dsDNA and antissDNA by about $40 \%$ of the original titre. Immune complexes decreased by as much as IgG antidsDNA. On the other hand, the recovery rate of anti-nRNP was $0.919(0.064)$, indicating that antiRNP was scarcely removed. Recovery rates of serum $\operatorname{IgG}, \operatorname{IgM}, \operatorname{IgA}, \mathrm{C} 3$, and $\mathrm{C} 4$ were almost the same as that of anti-nRNP. Biochemical data, such as albumin, showed no change except for total cholesterol, triglyceride, low density lipoprotein, and very low density lipoprotein.

To evaluate the efficiency of the removal the value of the trapping coefficient $f$ was calculated $(\mathrm{f}=1-\mathrm{Ca} / \mathrm{Cb}$, where $\mathrm{Ca}$ and $\mathrm{Cb}$ are the concentrations of a plasma component after and before the immunoadsorbent column respectively). The trapping coefficient is 1.0 when adsorption is complete and gets smaller as the capacity for adsorption becomes lower. Figure 2 shows the titre of IgG antidsDNA of plasma before and after the immunoadsorbent column, and its trapping coefficient, at times when each 0.5 litre of plasma had been treated (a), and that of low density lipoprotein-cholesterol and its trapping coefficient (b). As the plasma treatment went on the titre of anti-dsDNA in plasma before the column continued to decrease as did that of low density lipoprotein. The trapping coefficient of anti-dsDNA was, however, reduced in proportion to the treated plasma volume, whereas that of low density lipoprotein was unchanged during the procedure.

\section{Discussion}

Seventy seven per cent of anti-dsDNA in the circulation could be removed selectively and safely by immunoadsorption using the Liposorber. AntidsDNA has been shown to bind not only to DNA, but also to hyaluronic acid, chondroitin sulphate, and heparan sulphate, which contain repeating negatively charged units. ${ }^{2}$ The mechanism of the removal by the Lipsorber is, therefore, thought to be by cross reactivity of anti-dsDNA with dextran sulphate, which also has repeating negatively charged units.

Immune complexes were removed as well as anti-dsDNA, though the mechanism is unknown. Anti-nRNP, on the other hand, was hardly removed. Anti-nRNP is thought to be an autoantibody with high specificity in comparison with
anti-dsDNA or rheumatoid factor, and shows no cross reactivity. Plasma immunoglobulin was also hardly removed. As the recovery rate of $\mathrm{IgG}$ was 0.945 and the precipitation patterns of IgG in plasma before and after immunoadsorption in immunoelectrophoresis showed little difference (data not shown), the possibility that dextran sulphate removes the positively charged immunoglobulin non-selectively through electrostatic power seems unlikely.

Biochemical data such as albumin, except for total cholesterol, triglyceride, low density lipoprotein, and very low density lipoprotein, showed no significant changes during immunoadsorption. This selectivity made it unnecessary to use plasma substitute. Total cholesterol, triglyceride, low density lipoprotein, and very low density lipoprotein returned to their original levels within a week with no overshoot (data not shown). Such a transient reduction of lipid would produce no clinical problems.

Treatment of two litres of plasma led to the removal of about $40 \%$ of the anti-dsDNA. This efficiency is almost the same as that for removal of autoantibodies by plasma exchange. ${ }^{7}$ The value of the trapping coefficient $f$ showed, however, that the capacity of the Liposorber for anti-dsDNA was much smaller than that for low density lipoprotein. Low density lipoprotein, with a molecular weight about 10 times that of IgG, may sterically inhibit the binding of anti-dsDNA to dextran sulphate, or apoprotein B in low density lipoprotein may have higher affinity for dextran sulphate than anti-DNA.

Columns which employ biological substances, such as DNA as used by Terman et al, ${ }^{8}$ have problems for general use. Difficulties include obtaining sufficient amount of material, preventing it from degenerating, and keeping it biologically active as well as the problem of sterilisation. Moreover, these materials may immunise the patients because of their heterogeneity and leak into the circulating blood to form immune complexes. In a study of the selective removal of low density lipoprotein ${ }^{3}$ dextran sulphate has been shown to have no antigenicity to humans as we also showed in this study.

The removal of anti-dsDNA, which is believed to play a major part in the pathogenesis of SLE, especially lupus nephritis, is expected to be an effective treatment for SLE, even though soluble mediators rather than anti-dsDNA may cause some of the clinical symptoms of SLE. In our patient clinical improvement was not clear after efficient removal of anti-dsDNA by immunoadsorption. This was partly because disease activity had already been suppressed by treatment with prednisolone, but also 
the anti-dsDNA removed by the Liposorber might not have played a major part in the clinical symptoms in this patient, who had not suffered from nephritis, and soluble mediators might have exerted a greater effect.

In conclusion, selective removal of anti-dsDNA would contribute not only to the treatment of patients with SLE, but also to elucidation of the precise role of this antibody in the pathogenesis of SLE. Plasma exchange or double membrane filtration plasmapheresis can also reduce anti-dsDNA. In such cases, however, the mechanisms of improvement are not clear because not only antibodies other than anti-dsDNA but also soluble mediators are non-selectively removed from the circulation. As the selectivity of the removal of substances improves the mechanisms of plasmapheresis may also become clear. Application of this immunoadsorption treatment to patients with SLE with greater clinical activity and a high titre of anti-dsDNA in a well controlled study will clarify the true efficacy of selective removal of anti-dsDNA, and we are now carrying out a multicentre trial to examine this aspect. Therefore, the findings reported herein should be viewed as a preliminary basis for future study.
This work was supported by a grant from the Research Committee for Autoimmune Disease, the Ministry of Health and Welfare, Japan.

\section{References}

1 Jones J V. Plasmapheresis in SLE. Clin Rheum Dis 1982; 8: 243-60.

2 Faaber P, Rijke T P M, van de Putte L B A, Capel P J A, $\stackrel{\mathbb{D}}{\varrho}$ Berden J H M. Cross-reactivity of human and murine anti-DNA صి antibodies with heparan sulphate. J Clin Invest 1986; 77: 1824-30.

3 Yokoyama S, Hayashi R, Satani M, Yamamoto A. Selective removal of low density lipoprotein by plasmapheresis in familial $\vec{\omega}$ hypercholesterolemia. Arteriosclerosis 1985; 5: 613-22.

4 Aotsuka S, Okawa M, Ikebe K, Yokohari R. Measurement of anti-double-stranded DNA antibodies in major immunoglobulin classes. J Immunol Methods 1979; 28: 149-62.

5 Uwatoko S, Aotsuka S, Okawa M, et al. Characterization of Clq-binding IgG complexes in systemic lupus erythematosus. $\vec{O}$ Clin Immunol Immunopathol 1984; 30: 104-16.

6 White P J, Hoch S O. Definition of the antigenic polypeptides $\mathcal{G}$ in the Sm and RNP ribonucleoprotein complex. Biochem Biophys Res Commun 1981; 102: 356-71.

7 Jones J V, Robinson M F, Parciany R K, Layfer L F, McLeod B. Therapeutic plasmapheresis in systemic lupus erythematosus: effect on immune complexes and antibodies to DNA. Arthritis Rheum 1981; 24: 1113-20.

8 Terman D S, Buffaloe G, Mattioli C, et al. Extracorporeal immunoadsorption: initial experience in human systemic lupus erythematosus. Lancet 1979; ii: 824-6. 